
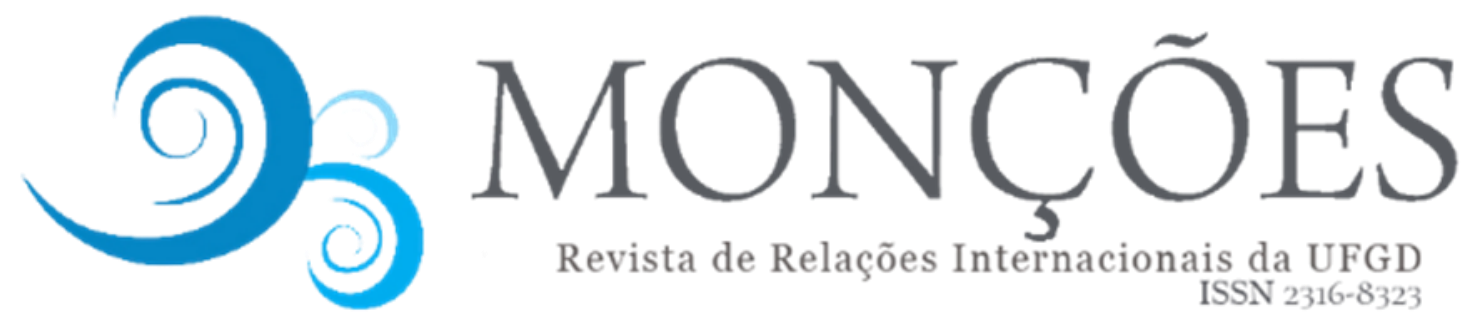

Revista de Relações Internacionais da UFGD

ISSN 2316-8323

\title{
Amazônia: palco de lutas e reflexões
}

\begin{abstract}
JOÃO NACKLE URT
Professor da Faculdade de Direito e Relações Internacionais da Universidade Federal da Grande Dourados (UFGD), Dourados (MS), Brasil.

ORCID: https://orcid.org/0000-0002-7785-2450

joaourt@ufgd.edu.br

MÁRCIO SECCO

Professor do Departamento de Filosofia da Universidade Federal de

Rondônia, Porto Velho, Brasil.

ORCID: https://orcid.org/0000-0001-7648-8522

msecco@unir.br
\end{abstract}

PATRÍCIA MARA CABRAL DE VASCONCELLOS

Professora do Departamento de Ciências Sociais (DACS) da Universidade

Federal de Rondônia (Unir), Porto Velho (RO), Brasil. ORCID: https://orcid.org/0000-0002-9077-8734 pvasconcellos@unir.br

Do início da colonização aos discursos de suposta internacionalização e perda de soberania até o entrelaçamento do seu tempo e espaço ao capitalismo global, as lutas que ocorrem na Amazônia refletem uma história que pode ser compreendida em termos de confronto entre modos de vida. Para as pessoas que residem na região, os indicadores são de maior vulnerabilidade e desigualdade social, violência na zona rural e urbana, dificuldade de acesso a serviços públicos e risco de morte aos defensores dos direitos humanos.

Nos noticiários recentes sobre a região amazônica brasileira percebemos a preocupação com a política governamental de exploração e devastação sem precedente da região. É a lógica de "passar a boiada" e das queimadas que colocam em risco as vidas amazônicas. A ideia do progresso a qualquer custo recupera a sua força, eliminando-se a capacidade de resistência, seja institucional, seja através de possibilidades de participação democrática dos movimentos sociais. Por mais chocantes que possam ser os acontecimentos atuais, estes podem ser lidos como uma consequência da visão geral que

Monções: Revista de Relações Internacionais da UFGD, Dourados, v.9, n.18, jul./dez.

Disponível em: http://ojs.ufgd.edu.br/index.php/moncoes

DOI 10.30612/rmufgd.v10i18.14401 
diferentes governos de diferentes países da América Latina tiveram, ao longo de séculos, sobre a Amazônia. Os projetos de desenvolvimento e integração não se dão a partir dos povos que ocupam a região nas fronteiras, mas a partir de projetos que buscam explorar o território e as riquezas disponíveis na região. É o que podemos ver nos diversos ciclos de exploração da Amazônia que se renovaram no início do século XXI com a Iniciativa para a Integração da Infraestrutura Regional Sul-Americana (IIRSA), em nível internacional, e com os Planos de Aceleração do Crescimento (PAC I e II), em nível nacional.

Os planos atuais de desenvolvimento são uma espécie de continuação ou reedição de projetos dos anos 70 de desenvolvimento para a Amazônia. Todos partem de exploração ambiental e aumento da população com ampliação da fronteira agrícola, liberação da mineração e outras atividades econômicas típicas da inserção dependente da região na ordem global. A lógica de modernização e ativação da economia por megaprojetos de infraestrutura voltados à viabilização da exploração do território persiste (CASTRO, 2012).

A lógica do mercado, para quem os sujeitos mais valiosos são commodities, faz com que culturas sejam dizimadas para que o gado possa se multiplicar, a mata derrubada para que a soja possa crescer, os rios e peixes represados para que as hidrelétricas possam gerar energia e o desenvolvimento, à base da exploração predatória, possa seguir. Mesmo aqueles que se voltam contra a exploração sem limites do território amazônico partem, em muitos casos, de uma lógica mercadológica para impedir a devastação atual. Becker (2009) alerta para o fato de que muitas potências internacionais veem na preservação ambiental uma forma de preservar estoques de natureza, que podem ser necessários e explorados no futuro, gerando riquezas pela exploração de estoques minerais, de terras férteis, biodiversidade ou mesmo com produção de fármacos.

Essa lógica, que vê a mata como obstáculo à agropecuária e outros empreendimentos, também torna as pessoas que não se adequam ao seu mecanismo de funcionamento, empecilhos. A falta de um olhar que possa perceber a imensa complexidade da realidade amazônica, desde sua diversidade cultural até diferentes perspectivas pelas quais se poderia tomar 
inclusive o território, joga tudo quanto possa ser estranho ao projeto traçado a partir de uma ótica reducionista no campo do empecilho, do obstáculo, do inimigo do desenvolvimento. É compreensível, assim, que a Amazônia seja um lugar de conflitos e disputas. Em muitos casos, esses conflitos assumem contornos de uma luta pela existência.

Essas lutas nos conduzem a outras reflexões. Lutas acirradas, levadas a extremos, que nos fazem lembrar a análise de Sassen (2016) quando afirma que para entender a desigualdade crescente é preciso ir além de conceitos familiarizados. No caso da Amazônia entendemos que é preciso relatar, pesquisar e analisar os extremos nos quais a região está imersa para compreender as brutalidades que são frequentemente produzidas. Assim, as lutas e reflexões poderiam ser interpretadas na esfera do que chamaríamos de "expulsões amazônicas", seguindo o termo "expulsões" cunhado por Sassen. A terminologia seria adequada para expressar o momento em que não se fala mais da mesma exploração, da mesma ameaça de morte e da mesma desigualdade, mas de algo que está no limite, no extremo da realidade, sendo produzido por uma forma particular de desenvolvimento econômico ou, como afirma a autora, do aprofundamento sistêmico das relações capitalistas. Assim, os fatos sociais na Amazônia são compreendidos dentro da dinâmica político-econômica global. As fronteiras amazônicas não estão isoladas, mas integradas ao processo do capital. A região está incorporada em fluxos de interesses que retratam a distribuição e uso desigual de seus recursos naturais.

Ainda devemos relembrar que há muitas "Amazônias" na Amazônia. A complexidade do território da Pan-Amazônia reside em suas especificidades políticas e socioculturais, interconectadas por fenômenos transnacionais ou globais. É espaço de modos de vida singulares, de resistência e de invenção de alternativas, inclusive sob a perspectiva da teorização política e jurídica

Diante disso, há uma série de políticas e fatos que demonstram a conjuntura da luta amazônica e que precisam ser observados no seu conjunto para conformar as tendências sistêmicas. Inicialmente podemos interligar as crises derivadas das queimadas, das invasões em terras indígenas, dos conflitos agrários, conflitos ambientais decorrentes de exploração de recursos naturais e 
de construção de grandes obras, do avanço da agropecuária, da violência urbana, entre outras.

Na Amazônia, os focos de queimadas em 2020, no mês de outubro, já eram superiores aos registrados em 2019 que, por sua vez, já haviam sido $30 \%$ maiores que os do ano anterior. Os estados com maior número de queimadas, em 2020, foram Pará, Mato Grosso, Amazonas e Rondônia. No mesmo ano, as queimadas na região do Pantanal registravam recordes. Segundo o Inpe, o Pantanal registrou em setembro de 2020, o número mensal mais alto de focos de incêndio desde o início da série histórica do Inpe, em 1998. Mais queimadas, mais devastação que implicam na incorporação da região em uma lógica sistêmica de desigualdade global.

Ao mesmo tempo em que áreas são devastadas pelas queimadas, ocorre a invasão de terras indígenas. Os conflitos por terra são recorrentes na história amazônica. Há a disputa por terra com trabalhadores rurais e também a invasão e a exploração de recursos em terras indígenas. As terras indígenas têm sido pressionadas pela devastação, mas também pelo narcotráfico, pela extração de madeira, pelo garimpo, pela caça e pesca ilegais. Povos em isolamento voluntário e de contato recente têm sofrido ataques genocidas desses invasores, como ocorreu na região do Xinane, Acre, em 2014, e na terra indígena do Javari, em 2017. Criminosos fortemente armados atravessam a fronteira com o Peru para disparar contra vilarejos indígenas em território brasileiro, com vítimas fatais (SILVA, 2016, p. 317-ss) Os Yanomami enfrentam há décadas a ocupação de suas terras por dezenas de milhares de garimpeiros, que contaminam suas águas com mercúrio e promovem ataques armados contra suas comunidades, repetindo - pela omissão do Estado - massacres como o de Haximu, ocorrido em 1993, que se tornou célebre pelo reconhecimento judicial do crime de genocídio. O Conselho Indigenista Missionário (2020) apontou que no primeiro ano de governo Bolsonaro as invasões em terras indígenas cresceram 135\%. Além disso, em decorrência das políticas governamentais, o IBAMA e a FUNAI têm perdido autonomia e capacidade de ação na defesa do meio ambiente e dos povos indígenas. 
Os conflitos não se restringem à Amazônia brasileira. O Peru, por exemplo, é citado por conflitos ambientais envolvendo a exploração de petróleo. Em destaque, a repressão ocorrida na província de Bagua, em 2009, em que houve manifestações contrárias à exploração de petróleo, gás, madeira e mineração, por parte da população indígena de Utcubamba e Bagua. Na ocasião, houve o bloqueio de estradas e a repressão resultou em 33 mortes, em 6 de junho do ano mencionado. A ameaça ambiental também foi relatada durante o ano de 2016, quando ocorreram vazamentos de petróleo no oleoduto, no norte do país. No início do referido ano houve vazamentos no departamento do Amazonas e, no Departamento de Loreto, no oleoduto da estatal Petroperú; em junho, foi na região de Loreto e agosto no distrito de Nieva. Como consequência, houve contaminação de terras pertencentes aos povos indígenas e contaminação das águas dos rios Chiriaco e Morona, tornando-as impróprias para o consumo (ANISTIA, Informe 2016/2017).

A região amazônica do Equador, por sua vez, apresenta-se como um dos casos emblemáticos de exploração da região - o caso Texaco/Chevron. A empresa que atuava na Amazônia norte do Equador foi acusada de poluir 480 mil hectares da floresta amazônica ao despejar aproximadamente 16 bilhões de litros de água tóxica. A União de Afetados pelas Operações da Texaco (UDAPT), que reúne cerca de 30 mil indígenas, move uma ação de reparação de danos contra a empresa desde 1993 (MENDOZA, 2017). Conflitos ambientais que se repetem e se agravam.

$\mathrm{Na}$ Amazônia brasileira tem-se a construção de grandes usinas hidrelétricas, tema abordado em diversos trabalhos ora publicados. A usina de Belo Monte, próxima ao município de Altamira, no norte do estado do Pará, foi concluída em 2019. O projeto, existente desde a década de 80 , teve resistência por parte de ambientalistas e comunidades indígenas, além de diversas suspensões para apurar irregularidades no empreendimento. Em Rondônia, a construção das usinas do Madeira (Jirau e Santo Antônio) teve o licenciamento ambiental contestado, mas a construção prosseguiu e os empreendimentos foram concluídos em 2017. Para viabilizar a construção das Usinas do Madeira e legitimar as ações compensatórias ao longo da execução das obras foram 
realizadas audiências públicas, um instrumento formal de participação nos processos de licenciamento ambiental, para que a população, em especial a diretamente atingida, pudesse ser informada sobre as ações das empresas. Contudo, há críticas com relação ao modo como eram realizadas as audiências desde o uso de linguajar excessivamente técnico e formal dificultando a compreensão das reais consequências para os atingidos até sua utilização como mera formalidade, desinteressada em promover o diálogo com a população afetada.

Embora em termos de discurso, inclusive internacional, o Brasil proclame uma preocupação ambiental e com a sustentabilidade da Amazônia, o que tem ocorrido no governo Bolsonaro é um agravamento de uma política nacional que leva ao extremo a decisão econômica de flexibilizar normativas ambientais objetivando permitir a construção de hidrelétricas e desmatamento para fins diversos, com a justificativa de que o desenvolvimento econômico proporciona progresso e riqueza para a população local.

Adicionalmente, a esse conjunto de fatos, há a expansão do agronegócio. Em Rondônia, por exemplo, a participação da atividade no PIB do estado de acordo com o valor adicionado bruto, cresceu de 11\% em 2010 para 15\% em 2017. Só em 2017, o aumento atribuído ao setor foi de 9,4\%. Segundo relatório da The Food and Agriculture Organization (FAO) de 2016, 0 agronegócio gerou quase $70 \%$ do desmatamento na América Latina entre 2000 e 2010. De acordo com a pesquisa, de 1990 e 2005 mais de $80 \%$ do desmatamento no Brasil era devido à conversão de terras em terrenos de pasto. A relação entre a expansão do agronegócio e os conflitos socioambientais na Amazônia permite entender certas escolhas sobre o processo de desenvolvimento e suas exclusões.

Conflitos ambientais, desmatamento, invasões de terras, vulnerabilidade social são situações que se entrelaçam para contribuir com o fato descrito no relatório Global Witness de 2018, o qual constata que o Brasil é o país que mais mata ativistas no mundo. No total foram elencados 207 assassinatos no mundo em 2017, dos quais 57 ocorreram no Brasil. Para além 
disso, o relatório ainda destaca que quase $80 \%$ dos defensores mortos no Brasil estavam ligados à defesa da Amazônia (GLOBAL WITNESS, 2018)

No contexto da pandemia de Covid-19, as circunstâncias agravantes se somam e sem diretriz de política pública de saúde, a região amazônica brasileira, tristemente representada por Manaus, no início de janeiro de 2020, viu-se isolada, sem oxigênio para tratamento de pacientes. Uma situação de crise que evidencia ainda mais as desigualdades regionais, as falácias que justificam projetos de desenvolvimento e de políticas públicas. Ademais, os acontecimentos recentes em praticamente todos os países da região (Bolívia, Brasil, Colômbia, Equador), apenas para ficar nos mais evidentes, oscilando entre golpes de estado de extrema-direita e respectivas resistências populares, sugerem reflexões sobre os rumos da região em termos de democracia, sustentabilidade, legitimidade e direitos. As dinâmicas humanas envolvendo a Amazônia como espaço de origem e destino de migrantes e refugiados também se apresentam como quebra-cabeças instigantes para os pesquisadores do social.

Narrativas reiteradas que precisam ser cientificamente avaliadas. Para além, a Amazônia precisa alcançar com seus pesquisadores e estudos o espaço científico para ser conhecida sem mitos e má retórica. O Dossiê "Amazônia: Palco de Lutas e Reflexões" certamente traz a sua contribuição nesta jornada. A região é marcada por desigualdades sociais profundas e dinâmicas típicas da última grande fronteira do mundo. Por outro lado, possui concepções próprias para o desenvolvimento, que ora se propõem aplicar sua ortodoxia, ora ressignificar o termo, reinventando-o: pós-desenvolvimento e pósextrativismo, bem viver e dignidade. De qualquer forma, o desafio de transformar a realidade é posto cotidianamente diante de nós e, à luz da pesquisa científica de qualidade, impõe-se o dever de apontar caminhos.

Breve panorama dos textos do Dossiê

As muitas vozes que se somam neste dossiê trazem, em resposta à nossa convocatória, pesquisas as mais variadas, com diferentes aportes 
empíricos e teóricos que dão uma pequena amostra da diversidade histórica, geográfica, social, cultural e política que compõe a Amazônia.

Já na entrevista, a advogada boliviana Maria Elena Attard Bellido ensina sobre inovações no sistema jurídico boliviano, direitos da natureza, movimentos indígenas, e outros temas de interesse para a Amazônia, em particular, e para a América Latina, em geral. Na seção de traduções, Rafael Alexandre Mello traz, em língua portuguesa, um trabalho de Cristina Inoue, originalmente publicado na revista Global Environmental Politics, que, por meio da abordagem teórica dos muitos mundos (worlding e worldism, no original), propõe um caminho para a interação entre os mundos do ambientalismo de matriz ocidental e os mundos indígenas na Amazônia.

Quem abre a seção de artigos inéditos é o trabalho de Lucas Guerra. Com base no estado-da-arte sobre a temática, o autor partiu de uma análise dos lugares da Amazônia na produção brasileira em Relações Internacionais para, em seguida, apontar a alternativa oferecida pelo Encontro Amazônia Centro do Mundo (EACM). O estudo desse evento, ocorrido em novembro de 2019 em Altamira (PA), com a presença de diversos atores sociais- indígenas, ribeirinhos, agricultores, cientistas, etc. - indica que o foco em dimensões do poder ainda marginalizadas - como etnia, raça e gênero - pode contribuir para que novas abordagens floresçam nas $\mathrm{Rl}$ a partir da Amazônia.

Em seguida, Brenda Cardoso de Castro denuncia o compromisso da noção eurocêntrica de tempo com a colonialidade. Daí em diante, e com apoio em conhecimentos críticos, em especial de vozes indígenas, a autora revira as noções de passado, presente e futuro em prol de uma necessária discussão sobre a Amazônia imaginada e a força do imaginário sobre a Amazônia. Colocase em questão a ideia de fim do mundo, a posicionalidade dos diversos sujeitos e seus envolvimentos em visões de mundo opostas: uma baseada no objetivo do lucro, outra, na defesa da vida. O trabalho torna-se ainda mais interessante lido em diálogo com o artigo que o sucede.

Igor Ribeiro e Estevão Fernandes aportam uma crítica da interseccionalidade e da colonialidade como chaves para interpretar os direitos humanos. Na esteira da melhor tradição antropofágica, os autores se propõem 
deglutir para superar esses termos que se tornaram figuras frequentes no jargão acadêmico. Com uma leitura afiada, esses sujeitos amazônicos contemporâneos oferecem um exercício teorizante que transborda o local e o particular.

Outra leitura amazônica dos direitos humanos vem de Matheus da Silveira e Natália de Sousa. Os pesquisadores discutem a ideia de saúde mental como componente do conceito de desenvolvimento, em face da multitude de experiências sociais que a Amazônia abarca. Seus resultados enfatizam a necessidade de que os Objetivos de Desenvolvimento do Milênio (ODS) sejam percebidos dentro de seu contexto e sejam abordados com especial ênfase para os direitos coletivos.

Quanto aos atores sociais que ocupam este palco, Luana de Moura e Maxim Repetto analisam o papel político das sujeitas organizadas em torno da Organização das Mulheres Indígenas de Roraima (OMIR). Além de vasta pesquisa documental, o trabalho resulta ainda de entrevistas com mulheres de destaque na história dessa organização. O artigo historiciza o surgimento da OMIR e enfatiza o protagonismo dessas mulheres na luta pela demarcação de terras indígenas em Roraima bem como em outros temas e agendas: como violência contra a mulher, alcoolismo, educação e saúde. Ressalta-se também sua perspectiva peculiar que se percebe como complementar à dos homens indígenas e distinta em relação ao feminismo (de matriz ocidental).

Também com uma visão voltada para as pessoas que fazem a história da Amazônia, Marco Antônio Domingues Teixeira narra a chegada dos nordestinos a Porto Velho para o trabalho de extração da borracha na década de 1940, apelidados pejorativamente de "arigós". O autor conta sobre o fluxo humano do Nordeste para o Norte que, nesse momento particular, foi conduzido e orientado pelo autoritarismo do estado varguista - com suas crenças racistas, eurocêntricas, higienistas - em função da extração de borracha para apoiar o esforço aliado na Segunda Guerra Mundial.

A história de outro projeto de intervenção autoritária chega ao dossiê através de Leonardo Evedove. O pesquisador traz um estudo crítico sobre o Programa Calha Norte (PCN) entre 1985 e 2018. O autor mostra como o PCN promove uma construção discursiva da Amazônia como vazio de poder, a fim de 
afirmar as instituições militares como atores privilegiados para atuar nesse imenso espaço. Com isso, o Programa perpetua a promoção de uma noção unilateral de desenvolvimento, isto é, em que prevalece o binômio segurançadesenvolvimento vindo das Forças Armadas, sem participação das sociedades afetadas pelas políticas públicas que promove.

Com um olhar para aspectos estruturais, Bruna Huertas mostra como, a despeito do avanço jurídico-institucional decorrente da constitucionalização do buen vivir e dos direitos da natureza na Bolívia, como o crescimento da demanda chinesa por commodities deu fôlego a um novo ciclo extrativista, com profundas externalidades negativas. Com base na proposta político-epistêmica das Epistemologias do Sul, a autora correlaciona investimentos chineses e impactos socioambientais, a partir do estudo do avanço da monocultura em decorrência das obras rodoviárias dentro da Terra Indígena e Parque Nacional Isiboro Sécure (TIPNIS).

Os cinco últimos artigos focam o tema das hidrelétricas na Amazônia, assunto que, como indica a proporção que ganhou neste dossiê, tem despertado interesse e reação por parte de acadêmicos e atores sociais afetados.

Sobre o tema, Luís Novoa Garzon procura explicar como se deu a reversão do papel ativo que o Brasil exerceu no processo de integração energética regional. A resposta passa pela privatização da estrutura nacional de geração de energia elétrica e pelo sucateamento do aparato nacional de regulação e coordenação econômicas, mas também pela presença avassaladora de capitais norte-americanos e chineses na região.

Luciana Mourão Borges, por sua vez, olha para as responsabilidades do Estado brasileiro nesse processo. A autora propõe uma análise do impacto das usinas hidrelétricas executadas por meio do Projeto de Aceleração do Crescimento (PAC), dos governos Lula e Dilma (2007-2014), baseada em trabalho de campo junto a uma variedade de sujeitos sociais que compõem o Movimento de Resistência aos conflitos e violações de direitos decorrentes dessa ação governamental. O artigo se concentra nos projetos de Jirau e Santo Antônio, em Rondônia, e São Luiz do Tapajós e Belo Monte, no Pará. 
Fernanda Sant'Anna, Raí Honorato e Pedro Henrique Bortoletto abordam a questão das hidrelétricas por duas perspectivas. De um lado, identificam a mobilização de aspectos técnicos referentes à construção das usinas de Santo Antônio, Jirau e Belo Monte como estratégia discursiva destinada a despolitizar o seu debate. De outro, trazem as iniciativas dos movimentos sociais e povos indígenas como tentativas de apontar o caráter eminentemente político das escolhas que resultam nessas obras.

Adriele Précoma, Adriano Braun e Liana Lima da Silva demonstram a ilegalidade do projeto de Usina Hidrelétrica Castanheira, no Mato Grosso. O projeto viola uma série de preceitos jurídicos, que o trabalho sintetiza em torno do conceito de direito de existência: tal empreendimento energético comprovadamente ameaça a existência de diversas formas de vida, sobretudo de povos cuja presença nesses territórios data de tempos imemoriais.

Ricardo da Costa e Silva, Gisele Cunha e Rebeca Ferreira, numa parceria entre Universidade e Ministério Público Federal, oferecem uma análise alarmante sobre a alienação de territórios sociais causada pela instalação de usinas hidrelétricas. A partir do estudo empírico do projeto da Usina Hidrelétrica de Tabajara, em Rondônia, as autoras indicam que a imposição de um uso corporativo do território em decorrência desses empreendimentos tem gerado um passivo social de grandes dimensões, com danos diretos para pescadores, ribeirinhos, extrativistas e diversos povos indígenas, inclusive isolados, e danos indiretos para todo o País.

Somados, os trabalhos trazem um repertório de peso, com contribuições oriundas de quatro universidades amazônicas (UNIR, UFRR, UFPA e UNAMA), além de quatro outras universidades brasileiras (PUC-RJ, UFABC, Unesp e UFGD), uma organização não-governamental (Operação Amazônia Nativa - MT) e o Ministério Público Federal sediado em Rondônia. A realização deste dossiê contou com a contribuição de dezenas de pareceristas anônimos sediados em universidades nacionais e internacionais, bem como com o apoio dos editores, Bruno Bernardi, Déborah Monte e Matheus Hernandez. A todas essas pessoas que tornaram possível esta publicação, agradecemos imensamente. 
Enfim, é com alegria que observamos, apesar do momento dramático que vivemos, a presença de massa crítica devotada à compreensão das dinâmicas amazônicas. Acreditamos que somente com base na seriedade deste esforço será possível apoiar lutas populares e pensar uma saída soberana para os desafios atuais.

\section{Referências}

ANISTIA [Anistia Internacional]. Informes Anuais. Disponível em: <https://anistia.org.br/direitos-humanos/informes-anuais/>. Acesso em: 5 set. 2019.

BECKER, B. Amazônia: Geopolítica na virada do III Milênio. Rio de janeiro: Garamond, 2009

CASTRO, E. Expansão da Fronteira, megaprojetos de infraestrutura e integração sul-americana. Cadernos CRH, Salvador, V.25, n64, p.45-61, jan-abr. 2012

CIMI. Relatório Violência contra os Povos Indígenas do Brasil - dados de 2019. Conselho Indigenista Missionário. Disponível em: <https://cimi.org.br/wpcontent/uploads/2020/10/relatorio-violencia-contra-os-povos-indigenas-brasil2019-cimi.pdf> Acesso em 12 dez. 2020.

FAO. El Estado de los bosques del mundo 2016. Los bosques y la agricultura: desafíos y oportunidades en relación con el uso de la tierra. Roma. 2016.

GLOBAL WITNESS. Relatório. A que preço? Negócios irresponsáves e o assassinato de defensores da terra e do meio ambiente em 2017. Publicado em $2018 . \quad$ Disponível em: $<$ https://www.globalwitness.org/en/campaigns/environmental-activists/a-quepre\%C3\%A7o/>. Acesso em: 10 set. 2018.

MENDOZA, Pablo Fajardo. Vazio Jurídico e abuso corporativo: caso Chevron. In: Transnacionais e Direitos Humanos. América Latina em movimento, 520, Ed. português, jan. 2017.

SASSEN, Saskia. Expulsões. Brutalidade e complexidade na economia global. Trad. Angélica Freitas. Rio de Janeiro: Paz e Terra, 2016.

SILVA, Rodolfo llário da. "Povos indígenas em isolamento voluntário na Amazônia brasileira: o sexto século de genocídios e diásporas indígenas". Tese (Doutorado em Relações Internacionais). Universidade de Brasília, Brasília, 2017. 